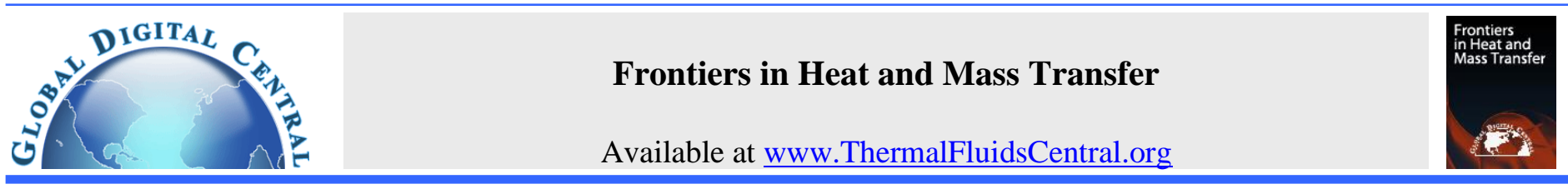

\title{
EXPERIMENTAL RESEARCH ON THE HEAT TRANSFER CHARACTERISTICS OF NANOFLUIDS IN CRUDE OIL HEATING FURNACES
}

\author{
Yun $\mathrm{Hao}^{*}$, Shaohua Lv, Song Wu \\ Mechanical Engineering College, Xi'an Shiyou University, Xi'an, 710065, China
}

\begin{abstract}
Traditional methods of enhancing the thermal efficiency of heating furnaces in continuously producing oilfields, such as replacing existing units with more efficient units or renovating old furnaces, are highly inconvenient. This paper studied on the characteristics of nanofluids, a novel heat transfer medium with excellent heat transfer characteristics to enhance the thermal efficiency of heating furnaces. The stable nanofluids $\left(\mathrm{Al}_{2} \mathrm{O}_{3}-\mathrm{H}_{2} \mathrm{O}, \mathrm{SiO}_{2}\right.$ $\mathrm{H}_{2} \mathrm{O}$, and $\mathrm{TiO}_{2}-\mathrm{H}_{2} \mathrm{O}$ ) were prepared by a two-step method and various chemical and physical treatments were carried out. Thermal conductivities of the nanofluids were measured using the transient hot-wire method. Based on the analysis, the most appropriate nanofluid $\left(\mathrm{TiO}_{2}-\mathrm{H}_{2} \mathrm{O}\right)$ was selected to carry out the field experiments in an oilfield in Xinjiang, China. And the results show that the $\mathrm{TiO}_{2}-\mathrm{H}_{2} \mathrm{O}$ nanofluid $(0.75 \%)$ can increase the thermal conductivity by $5.38 \%$ compared to pure water. Furthermore, the thermal efficiency of the heating furnace was enhanced by $10.57 \%$ and fuel consumption of the heating furnace was reduced by $14.8 \mathrm{~m}^{3} /$ day or $5400 \mathrm{~m}^{3} /$ year. The interesting findings reveal that nanofluids have the potential to improve the efficiency of heating furnaces in the heating, gathering and transportation systems of oilfield.
\end{abstract}

Keywords: Nanofluids; Heating furnaces; Heat transfer characteristics; Thermal efficiency; Field experiment

\section{INTRODUCTION}

Due to the sensitivity of crude oil to temperature, heating is often applied to enhance oil flow in order to improve the efficiency of oilfield gathering and transportation systems. At present, various heating methods are widely used in oilfields, such as heating furnaces, solar energy (Bierman B., et al., 2014), electric heating, and heat pumps (Mao N., et al., 2020). Currently, the average thermal efficiency of advanced industrial heating furnaces can reach $85-90 \%$; whereas, efficiencies of home furnaces still remain relatively low, around $80 \%$, due to larger excess air ratios, higher exhaust temperatures, and imperfect combustion. In oilfields, heating furnaces account for $25 \%$ of the total energy consumption of the system. However, traditional methods for improving the thermal efficiency of heating furnaces, such as replacing older units with more efficient ones or renovating old furnaces, are inconvenient, especially in continuously producing oilfields; therefore, novel heat transfer media for enhancing thermal efficiency are highly desirable.

Nanofluids firstly proposed by Argonne National Laboratory in 1995 were suspensions of nanometer-sized metal or nonmetallic oxide particles. In the heat-transfer processes, nanofluids exhibited a number of attractive properties as the working medium, including their high thermal conductivities (Nazari M.A., et al., 2018, Sheikholeslami M., 2018). These improved thermal properties are likely due to the increased surface area and high thermal conductivity of the suspended nanoparticles, as well as interaction and collision among particles, intensified mixing and turbulence, and molecular ordering at the liquidsolid interface. Thus, the high thermal conductivity of nanofluids can improve the thermal efficiency of heating furnaces.

As shown in Fig.1, the water-jacket furnace is commonly used in oilfields owing to sufficient fuels (oil or natural gas) and its sustainable operation. The fuel is first ignited in the burner and then flows through the refractory element, fire tube, and smoke tube of the combustion pass. As the burning fuel flows, heat is transferred through the wall of the smoke tube into the working fluid inside the furnace via radiation, convection, and conduction. The crude oil is heated by the working fluid as it passes through the heating coil of the furnace and is transported to the oil and gas transfer station. In the heat-transfer process, the working fluid (water) near the external surface of the smoke tube or fire tube is boiled, but it does not reach the saturation in other area. In other words, the whole water bath is under the subcooled boiling state. When nanoparticles are added to the water bath of heating furnace, the suspended nanoparticles are subjected to pool boiling conditions, and the boiling and heat transfer characteristics are very complicated.

Many researchers have studied the heat transfer coefficient (HTC) and critical heat flux (CHF) of nanofluids under pool boiling conditions, and debated the influence of nanofluids (Wang D.M., et al., 2018). In general, the heat transfer coefficient (HTC) and critical heat flux (CHF) of nanofluids were found to increase following the addition of nanoparticles, however, a few studies showed no change in the boiling HTC or even, deterioration of the HTC. Niu et al. (2015) investigated the characteristics of $\mathrm{Al}_{2} \mathrm{O}_{3}$ or $\mathrm{CuO}$ nanofluids with porous copper coatings under the pool boiling regime. The combination of the nanofluid with a porous surface was shown to enhance the HTC by more than $50 \%$. Similarly, Wen et al. (2011) studied the influence of aqueous alumina nanofluid concentrations $(0.001-0.1 \%)$ on the nucleate boiling HTC, which could be enhanced by up to $200 \%$ (currently the maximum value reported in the literature). Kamatchi et al. (2016) experimentally examined the CHF of graphene oxide/water nanofluids and showed that the CHF can be increased by $245 \%$ compared to the base fluid. Similarly, Amiri et al. (2014) reported an enhanced HTC of $270 \%$ for carbon nanotube-water nanofluids. However, Shahmoradi et al. (2013) showed 
HTC of $\mathrm{Al}_{2} \mathrm{O}_{3}$-based aqueous nanofluids (less than $0.1 \mathrm{vol} . \%$ ) on a flat plate under nucleate pool boiling is reduced by $40 \%$ when the ratio of average surface roughness to the average diameter of particles much less than one, whereas the CHF increased. Jung et al. (2012) measured the $\mathrm{CHF}$ and boiling HTC of a water-based $\mathrm{Al}_{2} \mathrm{O}_{3}$ nanofluid. As the concentration of nanoparticles increased, the boiling HTC of the nanofluid decreased to less than that of the base fluid, while the CHF increased. Furthermore, Kathiravan et al. (2010) showed that the CHF of $\mathrm{CuO}$-water nanofluids will deteriorate by up to $75 \%$ with the addition of chemical dispersant.

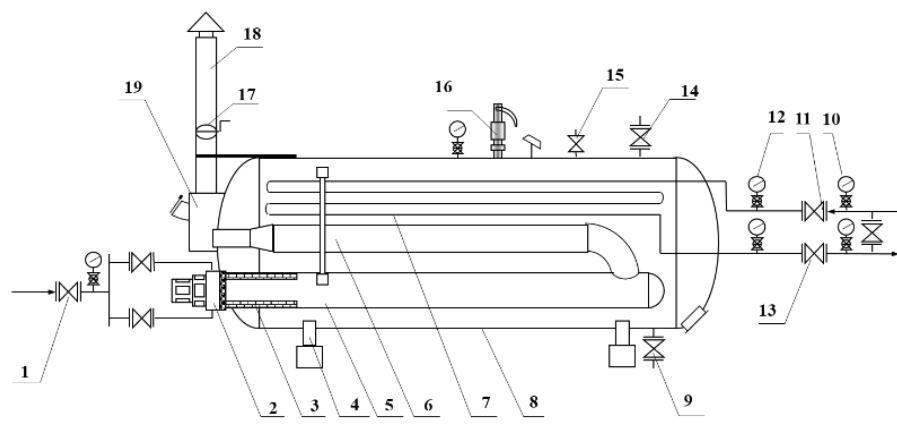

1 fuel control valve; 2 burner; 3 refractory combustion pass; 4 support; 5 fire tube; 6 smoke tube; 7 heating coil; 8 shell; 9 blowdown valve; 10 thermometers; 11 inlet valve; 12 pressure gauge; 13 outlet valve; 14 make-up valve; 15 vent valve; 16 safety valve; 17 smoke damper; 18 chimney; 19 smoke box

Fig. 1 Structure of water-jacket furnace

Compared with the research above mentioned, the heat transfer characteristics of nanofluids under subcooled boiling has been relatively less. Setoodeh H., et al. (2015) experimentally studied the effects of fluid velocity and channel surface roughness on the heat transfer characteristics of aluminum nanofluids under the condition of subcooled boiling. The results show that compared with pure water, the heat transfer coefficient of aluminum nanofluids increases with the increase of channel surface roughness and fluid flow velocity under both singlephase forced convection and subcooled boiling conditions. It was found by Kangude P., et al. (2018) that $\mathrm{SiO}_{2}$ nanoparticles could make the temperature distribution more uniform under the condition of subcooled boiling of $\mathrm{SiO}_{2}$-water nanofluids. Sarafraz M.M., et al. (2014) experimentally studied the influence of mass flow in a vertical annular channel on the heat transfer characteristics of $\mathrm{CuO}$ water-based nanofluids under forced convection and subcooled flow boiling conditions. It showed that with the increase of the nanofluid concentration and mass flow rate, the heat transfer coefficient of nanofluid increased in the forced convection and nuclear boiling regions. Dolatiasl K., et al. (2020) studied the critical heat flux density (CHF) of $\mathrm{Al}_{2} \mathrm{O}_{3}$-water nanofluid under subcooled boiling flowing in the tube. Increasing with the temperature of nano-fluid entering into the tube can reduce $\mathrm{CHF}$. As the pipe inclination increased, steam located in the upper part of the pipe wall, which can make CHF decreased. Therefore, it is necessary to further study on the heat transfer characteristics of nanofluids under subcooled boiling.

In this study, to investigate the actual effects of a nanofluid on the thermal efficiency of heating furnaces, not only in the laboratory, a novel heat transfer medium (nanofluid) was applied in an oilfield and the heat transfer characteristics were analyzed. Three different stable nanofluids were first prepared by a two-step method and their thermal conductivities were measured using the transient hot-wire method. Based on the results, an appropriate nanofluid was selected for the field experiment, which was performed in a crude oil field in Xinjiang, China. Finally, the thermal efficiency of heating furnace was obtained to verify the heat transfer characteristics of nanofluids under subcooled boiling.

\section{EXPERIMENTAL SETUP}

\subsection{Nanoparticle selection}

Three types of nanoparticles, $\mathrm{Al}_{2} \mathrm{O}_{3}, \mathrm{SiO}_{2}$, and $\mathrm{TiO}_{2}$, were selected for the experiment. Physical properties of the nanoparticles are listed in Table 1.

Table 1 Physical properties of nanoparticles

\begin{tabular}{|c|c|c|c|c|}
\hline $\begin{array}{l}\text { Type of } \\
\text { particles }\end{array}$ & $\begin{array}{l}\text { Purity } \\
(\%)\end{array}$ & $\begin{array}{l}\text { Particle Size } \\
(\mathrm{nm})\end{array}$ & $\begin{array}{l}\text { Flowing } \\
(\mathrm{sec} / 50 \mathrm{~g})\end{array}$ & $\begin{array}{l}\text { Density } \\
\left(\mathrm{g} / \mathrm{cm}^{3}\right)\end{array}$ \\
\hline $\mathrm{Al}_{2} \mathrm{O}_{3}$ & 99.99 & 20 & 19 & 3.1 \\
\hline $\mathrm{SiO}_{2}$ & 99.9 & 20 & - & 0.98 \\
\hline $\mathrm{TiO}_{2}$ & 99.99 & 20 & 17.85 & \\
\hline
\end{tabular}

\subsection{Base fluid}

Based on the quality of treated water in the oilfield in which the field experiment was carried out, inorganic salts were added to the deionized water, as listed in Table 2.

Table 2 Inorganic salts added to deionized water

\begin{tabular}{|c|c|}
\hline Components & Addition amount $(\mathrm{mg} / \mathrm{L})$ \\
\hline $\mathrm{NaCl}$ & 208.845 \\
\hline $\mathrm{NaHCO}_{3}$ & 111.72 \\
\hline $\mathrm{Na}_{2} \mathrm{SO}_{4}$ & 139.87 \\
\hline $\mathrm{MgSO}_{4}$ & 6.6 \\
\hline $\mathrm{CaCl}_{2}$ & 11.655 \\
\hline
\end{tabular}

\subsection{Chemical dispersants}

Three chemical dispersants were used in the experiment: sodium hexametaphosphate (SHP) which is an inorganic electrolyte, cetyltrimethylammonium bromide (CTAB) which is a cationic dispersant and acacia gum powder which is a nonionic polymer.

\section{STABILITY OF NANOFLUIDS}

Several studies have established that the dispersion and stability are the vital features in the improvement of the thermophysical properties (Abbud, L. H., et al., 2019, Teja,S.R., et al., 2020) of nanofluids, particularly for thermal conductivity. Colloidal fluids are assessed for stability utilizing variation of zeta potential of the fluid. The zeta potential specifies the amount of repulsion of charged particles The zeta potential of water mixed with nanoparticles is appraised to assess their stability.

\subsection{Effect of dispersants on nanofluid stability}

The nanofluids were prepared using a two-step method. First, a certain concentration of nanoparticles $\left(\mathrm{Al}_{2} \mathrm{O}_{3}, \mathrm{SiO}_{2}\right.$, or $\left.\mathrm{TiO}_{2}\right)$ and chemical dispersant (CTAB, SHP, or acacia gum powder) were mixed into the water, then mechanical agitation and ultrasonic dispersion were applied for $1 \mathrm{~h}$ at an ultrasonic power of $375 \mathrm{~W}$ to disperse the nanoparticles. Finally, stability of the resulting nanofluids was evaluated using the sedimentation method, particle size measurements, and zeta potential. The latter can be used to characterize stable nanofluids with large absolute zeta potential values.

Briefly, different concentrations of dispersant were added to the deionized water (mass concentration of $0.25 \%$ ). After mechanical agitation and ultrasonic dispersion, the particles were allowed to settle for $72 \mathrm{~h}$, then the zeta electric potential of the nanofluid was measured. The variation of zeta potential with chemical dispersant concentration is illustrated in Fig. 2-4.

The absolute zeta potential of the $\mathrm{Al}_{2} \mathrm{O}_{3}-\mathrm{H}_{2} \mathrm{O}$ nanofluid increased with increasing CTAB and SHP concentrations, as shown in Fig.2. The 
zeta electric potential peaked at about $51 \mathrm{mV}$ and the nanofluid exhibited the best stability when $0.06 \%-0.1 \%$ SHP was used as the dispersant. When the concentration of dispersant increased to greater than $0.125 \%$, the zeta potential was about $44 \mathrm{mV}$ for both the CTAB and SHP dispersants. Thus, it can be concluded that the CTAB and SHP dispersants have a smooth and steady effect on the stability of the $\mathrm{Al}_{2} \mathrm{O}_{3}-$ $\mathrm{H}_{2} \mathrm{O}$ nanofluid.

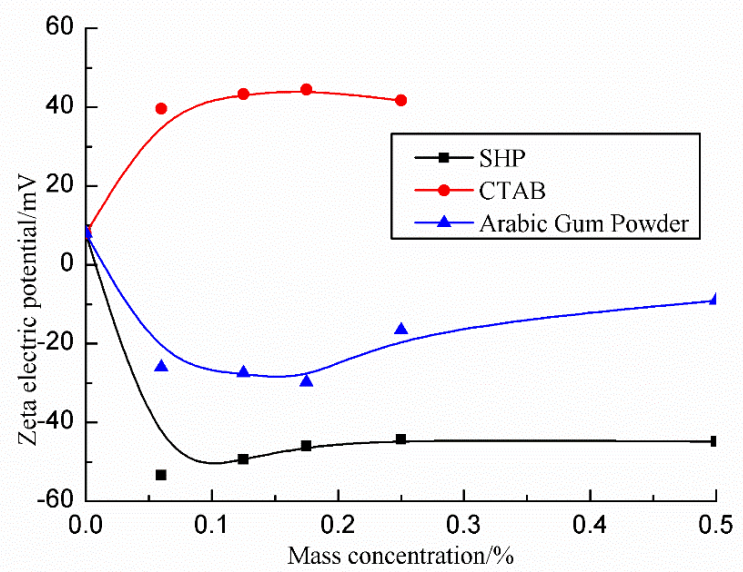

Fig. 2 Variation of zeta potential of $\mathrm{Al}_{2} \mathrm{O}_{3}-\mathrm{H}_{2} \mathrm{O}$ nanofluid with increasing chemical dispersants

Zeta potentials of the $\mathrm{Al}_{2} \mathrm{O}_{3}-\mathrm{H}_{2} \mathrm{O}$ nanofluid with $\mathrm{CTAB}$, SHP, and acacia gum powder dispersants were compared. The acacia gum powder resulted in poor stability regardless of concentration. For the $\mathrm{Al}_{2} \mathrm{O}_{3}-\mathrm{H}_{2} \mathrm{O}$ nanofluid, $0.1 \%$ SHP should be added to the base fluid as the dispersant. As shown in Fig.3, the absolute zeta potential of the $\mathrm{SiO}_{2}-\mathrm{H}_{2} \mathrm{O}$ nanofluid first increased with increasing SHP concentration, then reached a steady value at about $43 \mathrm{mV}$. The increasing CTAB concentration resulted in a parabolic (quadratic) trend with a maximum value of $50.66 \mathrm{mV}$ at a concentration $0.125 \%$ CTAB. Finally, the $\mathrm{SiO}_{2}-\mathrm{H}_{2} \mathrm{O}$ nanofluid with acacia gum powder as the dispersant had the poorest stability. For the $\mathrm{SiO}_{2}-\mathrm{H}_{2} \mathrm{O}$ nanofluid, the optimal dispersant is CTAB with a mass concentration of $0.125 \%$.

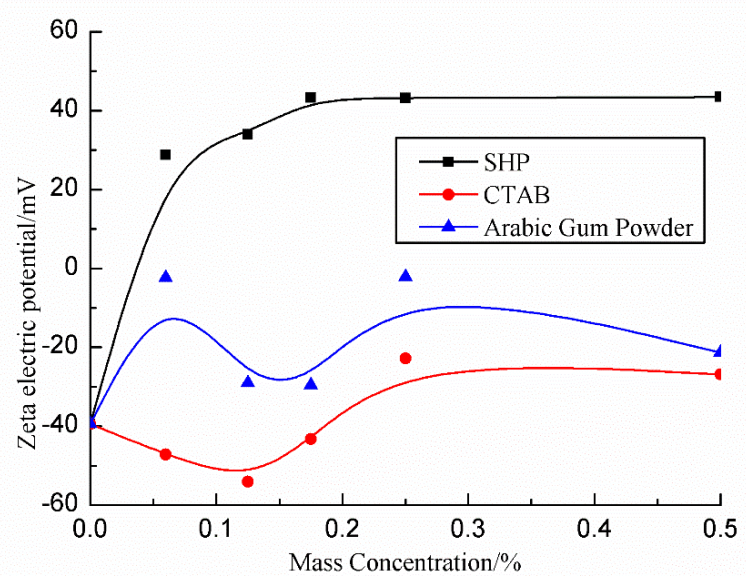

Fig. 3 Variation of zeta potential of $\mathrm{SiO}_{2}-\mathrm{H}_{2} \mathrm{O}$ nanofluid with increasing chemical dispersants

The zeta potential of the $\mathrm{TiO}_{2}-\mathrm{H}_{2} \mathrm{O}$ nanofluid varied with increasing chemical dispersant concentration, as shown in Fig.4. The SHP dispersant did not significantly improve the stability of the $\mathrm{TiO}_{2}-\mathrm{H}_{2} \mathrm{O}$ nanofluid until a mass concentration of $0.175 \%$ was reached. The stability of $\mathrm{TiO}_{2}-\mathrm{H}_{2} \mathrm{O}$ nanofluid with $\mathrm{CTAB}$ as the dispersant is superior to the stability when acacia gum powder is used, except at a mass concentration of $0.06 \%$. In this study, the $\mathrm{TiO}_{2}-\mathrm{H}_{2} \mathrm{O}$ nanofluid remained stable for the longest period of time when the CTAB dispersant with a mass concentration of $0.125 \%$ was added to the nanofluid.

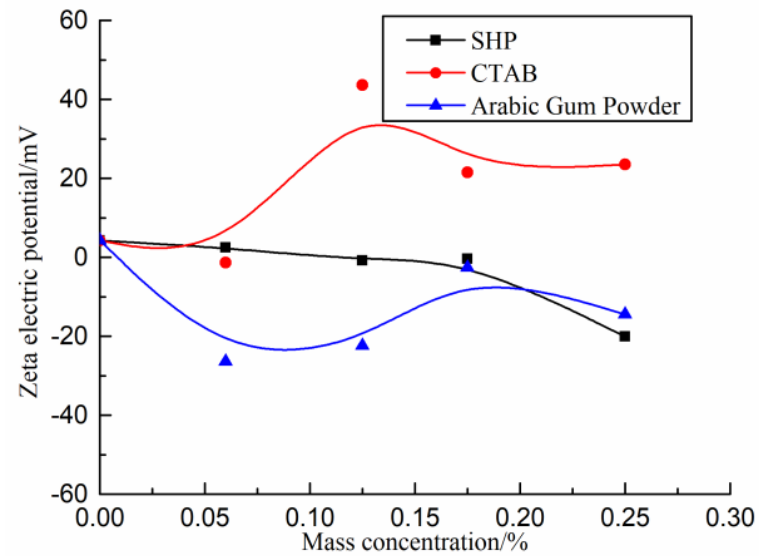

Fig. 4 Variation of zeta potential of $\mathrm{TiO}_{2}-\mathrm{H}_{2} \mathrm{O}$ nanofluid with increasing chemical dispersants concentration

\subsection{Effect of ultrasonic time on nanofluid stability}

On the microscale, the short wavelength of ultrasonic waves increases Brownian motion of nanoparticles and impacts the dynamic stability of base liquid, which can improve the uniformity and speed of nanoparticle dispersion. The energy generated by the ultrasonic dispersion method has a large influence on the stability of the nanofluid. Therefore, the influence of ultrasonic time on nanofluid stability was further investigated.

At a constant ultrasonic power, increasing the ultrasonic time increases the ultrasonic energy, which will, therefore, have a greater influence on nanofluid stability. The effects of ultrasonic time on the stability of the $\mathrm{Al}_{2} \mathrm{O}_{3}-\mathrm{H}_{2} \mathrm{O}, \mathrm{SiO}_{2}-\mathrm{H}_{2} \mathrm{O}$, and $\mathrm{TiO}_{2}-\mathrm{H}_{2} \mathrm{O}$ nanofluids are illustrated in Fig.5.

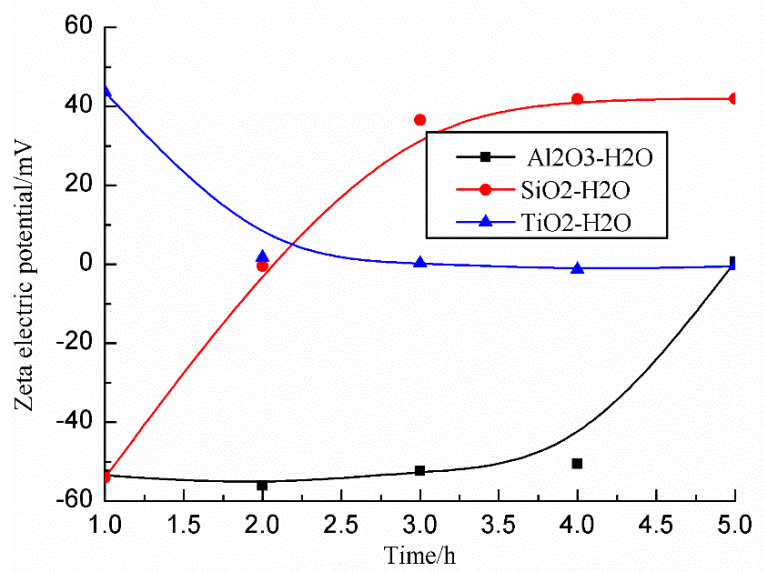

Fig. 5 Variation of zeta potential with ultrasonic time for $\mathrm{Al}_{2} \mathrm{O}_{3}-\mathrm{H}_{2} \mathrm{O}$, $\mathrm{SiO}_{2}-\mathrm{H}_{2} \mathrm{O}$, and $\mathrm{TiO}_{2}-\mathrm{H}_{2} \mathrm{O}$ nanofluids

The zeta potential of the $\mathrm{Al}_{2} \mathrm{O}_{3}-\mathrm{H}_{2} \mathrm{O}$ nanofluid varied as the ultrasonic time increases from $1 \mathrm{~h}$ to $4 \mathrm{~h}$ (Fig.5). However, as the ultrasonic time continuously increased, the zeta potential fell sharply due to particle collisions and coagulation, sedimentation, and particle dispersion effects. Thus, an ultrasonic time of less than $4 \mathrm{~h}$ should be selected in order to maintain the stability of the nanofluid. For $\mathrm{SiO}_{2}-\mathrm{H}_{2} \mathrm{O}$, the absolute zeta potential first decreased sharply, then a turning point occurred at $2 \mathrm{~h}$, and the zeta potential then gradually increased until reaching a steady state at $4 \mathrm{~h}$. It can be concluded that as the ultrasonic time increases, the stability first deteriorates, then gradually improves until the optimal stability is reached at $4 \mathrm{~h}$. When the ultrasonic time is 
very short, the energy generated is not sufficient to disperse the particles in the base fluid. As the ultrasonic time increases, the energy will also increase and the nanoparticles can resist agglomeration due to electrostatic attraction; thus, dispersion of the nanoparticles improves. However, Fig.5 suggests that before $2 \mathrm{~h}$, the ultrasonic time does not affect $\mathrm{TiO}_{2}-\mathrm{H}_{2} \mathrm{O}$ nanofluid stability, then after $2 \mathrm{~h}$, the stability begins to deteriorate with increasing ultrasonic time.

In summary, longer ultrasonic times do not improve the stability of the nanofluid and an appropriate ultrasonic time should be selected for the preparation of nanofluids.

\section{INDOOR EXPERIMENT ON THERMAL PERFORMANCE OF NANOFLUIDS}

To evaluate the thermal performance of the nanofluids, thermal conductivity was measured at the MOE Key Laboratory of Thermo-Fluid Science and Power Engineering of Xi' an Jiaotong University using the transient hot-wire method, as shown in Fig.6. Nanofluids with mass concentrations of $0.25 \%, 0.5 \%$, and $0.75 \%$ were tested at a system pressure of $0.15 \mathrm{MPa}$ in the temperature range of $40-75^{\circ} \mathrm{C}$.
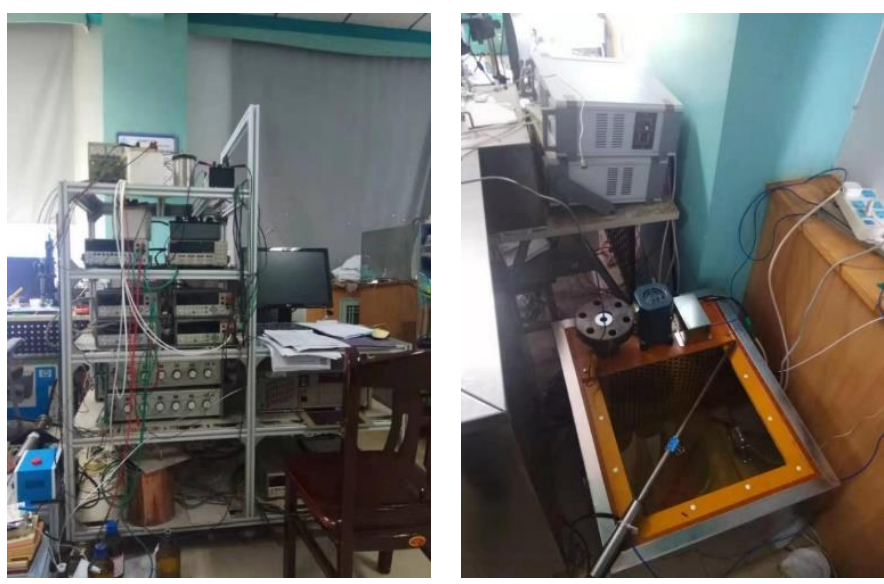

Fig. 6 Experimental platform for testing thermal conductivity of nanofluids

\subsection{Thermal conductivity of $\mathrm{Al}_{2} \mathrm{O}_{3}-\mathrm{H}_{2} \mathrm{O}$ nanofluid}

To verify the method, the thermal conductivity of pure water was first measured in the temperature range, as shown in Fig.7, and compared with data from the National Institute of Standards and Technology (NIST). The average absolute relative deviation was $0.64 \%$, thus verifying the accuracy and reliability of the experimental approach.

As illustrated in Fig.7, the thermal conductivity of the $\mathrm{Al}_{2} \mathrm{O}_{3}-\mathrm{H}_{2} \mathrm{O}$ nanofluid varied with both temperature and mass concentration. In general, the thermal conductivities of the nanofluids were larger than those of pure water and the largest increase was 3.65\%. For the same concentration of nanoparticles, the thermal conductivity increased exponentially with increasing temperature. However, increasing the nanoparticle concentration resulted in a decrease in thermal conductivity of the nanofluids at a temperature of $75^{\circ} \mathrm{C}$. when the concentration of nanoparticles was increased from $0.5 \%$ to $0.75 \%$, the thermal conductivity decreased from $0.685 \mathrm{~W} /(\mathrm{m} \cdot \mathrm{K})$ to $0.669 \mathrm{~W} /(\mathrm{m} \cdot \mathrm{K})$. As the temperature increased, Brownian motion of the nanoparticles accelerated and collision and coagulation, as well as sedimentation and dispersion effects were strengthened. In addition, when the water was close to the saturation temperature of $75^{\circ} \mathrm{C}$, a number of bubbles were generated in the water, which impeded the heat conduction process and reduced the thermal conductivity of the nanofluid. When the temperature was lower $\left(40^{\circ} \mathrm{C}\right)$, the effect of the concentration of nanoparticles on the thermal conductivity may be not obvious, even positive influences (Wu Z., et al., 2014). Thus, it can be concluded that selecting the appropriate nanoparticle concentration is important for achieving the desired thermal conductivity of the nanofluid.

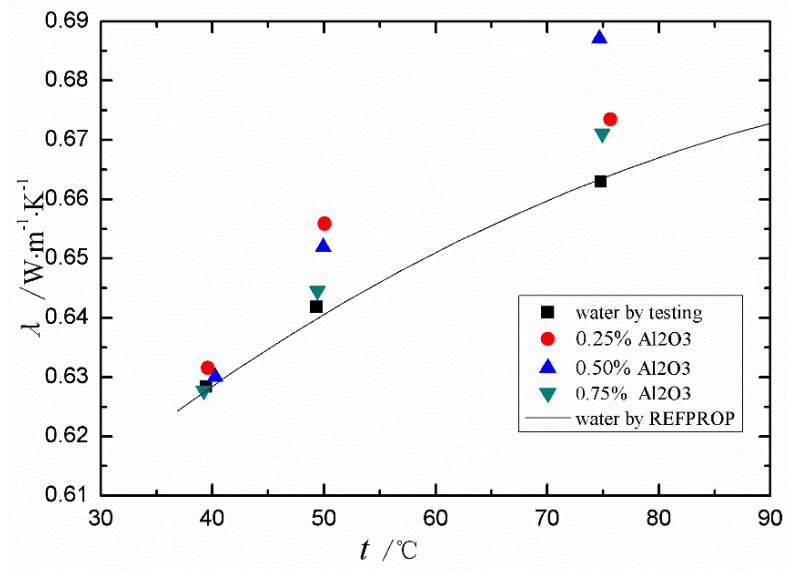

Fig. 7 Variation of thermal conductivity of $\mathrm{Al}_{2} \mathrm{O}_{3}-\mathrm{H}_{2} \mathrm{O}$ nanofluid with temperature and nanoparticle concentration

\subsection{Thermal conductivity of $\mathrm{SiO}_{2}-\mathrm{H}_{2} \mathrm{O}$ nanofluid}

Fig.8 shows the variation of thermal conductivity of the $\mathrm{SiO}_{2}-\mathrm{H}_{2} \mathrm{O}$ nanofluid with the nanoparticle concentration and working fluid temperature under consistent conditions. As the temperature increased from $40^{\circ} \mathrm{C}$ to $75^{\circ} \mathrm{C}$ at the same nanoparticle concentration, the thermal conductivity of the $\mathrm{SiO}_{2}-\mathrm{H}_{2} \mathrm{O}$ nanofluid reached a maximum value of $0.6776 \mathrm{~W} /(\mathrm{m} \cdot \mathrm{K})$, which is $2.29 \%$ higher than thermal conductivity of pure water. However, as the nanoparticle concentration increased from $0.25 \%$ to $0.75 \%$, in all cases, the thermal conductivity invariably increased from $6.42 \%$ to $6.62 \%$ as the temperature increased from $40^{\circ} \mathrm{C}$ and $75^{\circ} \mathrm{C}$. Therefore, it can be concluded the mass concentration of $\mathrm{SiO}_{2}$ nanoparticles has a relatively weak impact on thermal conductivity, similar to the effects of the $\mathrm{Al}_{2} \mathrm{O}_{3}$ nanoparticles; however, the increase in thermal conductivity is relatively small compared to the increase observed with the $\mathrm{Al}_{2} \mathrm{O}_{3}-\mathrm{H}_{2} \mathrm{O}$ nanofluid.

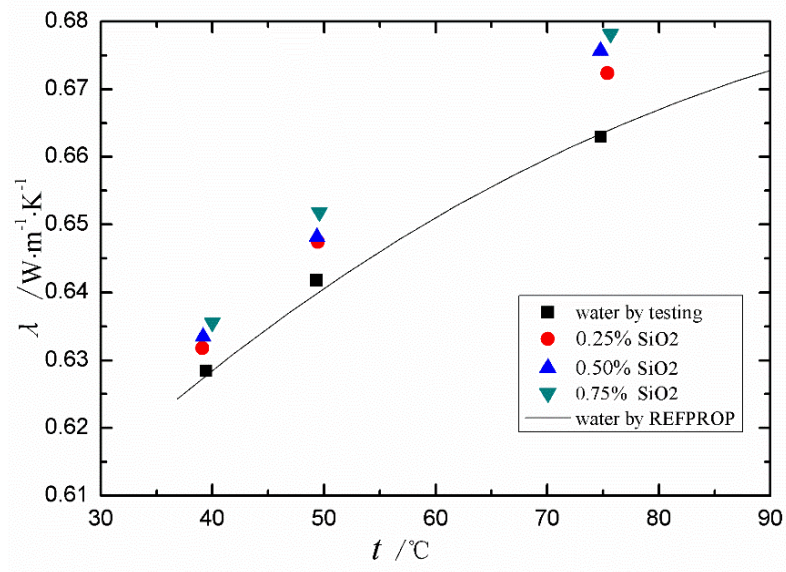

Fig. 8 Variation of thermal conductivity of $\mathrm{SiO}_{2}-\mathrm{H}_{2} \mathrm{O}$ nanofluid with temperature and nanoparticle concentration

\subsection{The thermal conductivity of $\mathrm{TiO}_{2}-\mathrm{H}_{2} \mathrm{O}$ nanofluid}

Fig.9 shows the variation of thermal conductivity of the $\mathrm{TiO}_{2}-\mathrm{H}_{2} \mathrm{O}$ nanofluid with nanoparticle concentration and temperature. At a nanoparticle concentration of $0.25 \%$, the thermal conductivity of the $\mathrm{TiO}_{2}-\mathrm{H}_{2} \mathrm{O}$ nanofluid increased from $0.6491 \mathrm{~W} /(\mathrm{m} \cdot \mathrm{K})$ at $40^{\circ} \mathrm{C}$ to $0.6789 \mathrm{~W} /(\mathrm{m} \cdot \mathrm{K})$ at $75^{\circ} \mathrm{C}$, representing an increase of $4.6 \%$. When nanoparticles were continuously added to base fluid, the thermal 
conductivity increased by $8.24 \%$ at a nanoparticle concentration of $0.75 \%$, which is almost double the thermal conductivity of the nanofluid with a nanoparticle concentration of $0.25 \%$. Compared with $\mathrm{Al}_{2} \mathrm{O}_{3}-\mathrm{H}_{2} \mathrm{O}$ and $\mathrm{SiO}_{2}-\mathrm{H}_{2} \mathrm{O}$, the thermal conductivity of the $\mathrm{TiO}_{2}-\mathrm{H}_{2} \mathrm{O}$ nanofluid varied more obviously with nanoparticle concentration and temperature. Thermal conductivity of the $\mathrm{TiO}_{2}-\mathrm{H}_{2} \mathrm{O}$ nanofluid was $5.38 \%$ higher than pure water; therefore, the $\mathrm{TiO}_{2}-\mathrm{H}_{2} \mathrm{O}$ nanofluid was selected as the optimal working fluid.

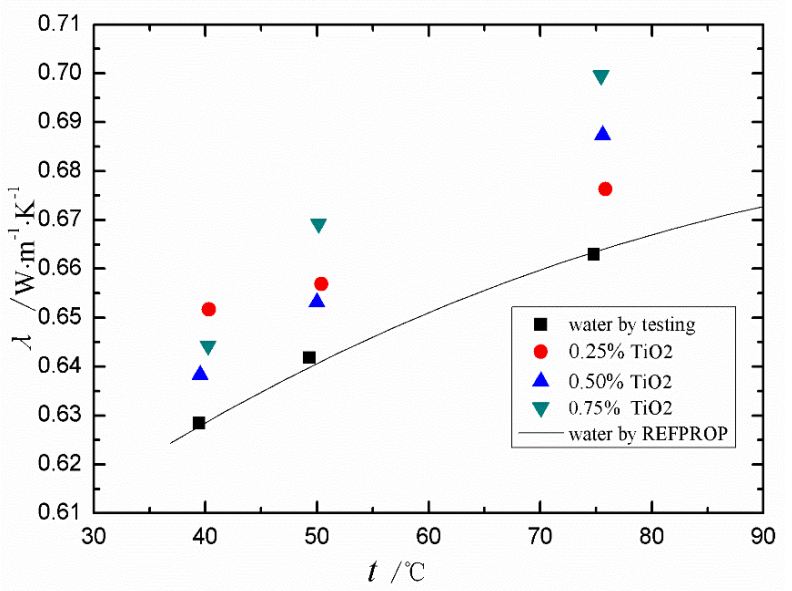

Fig. 9 Variation of thermal conductivity of $\mathrm{TiO}_{2}-\mathrm{H}_{2} \mathrm{O}$ nanofluid with temperature and nanoparticle concentration

\subsection{Effect of dispersant on the thermal conductivity of nanofluids}

A series of additional experiments were carried out to determine the influence of the type and concentration of dispersant on the thermal conductivity of the nanofluids. The results are presented in Fig.10.

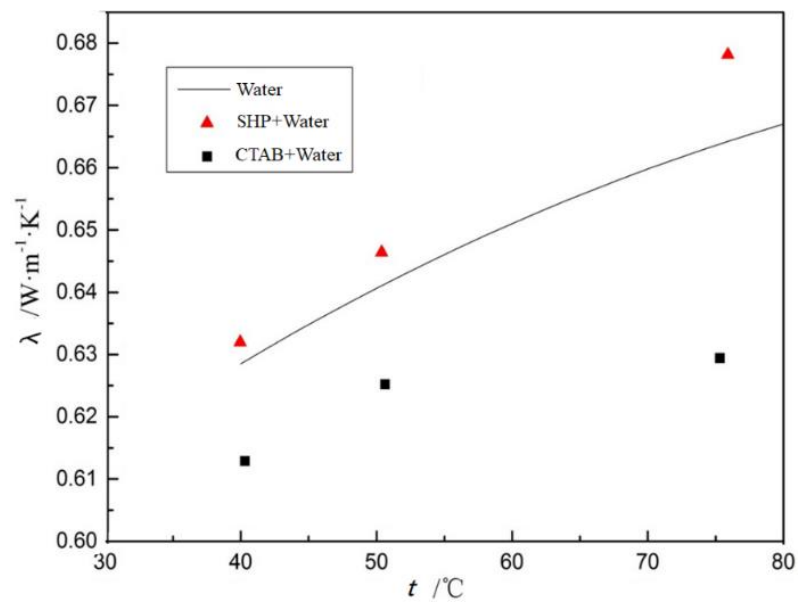

Fig. 10 Variation in thermal conductivity of SHP and CTAB dispersants with temperature

The maximum concentrations of the CTAB and SHP dispersants were $0.18 \%$ and $0.375 \%$, respectively (from Section 3). The thermal conductivity of pure water increases due to the participation of SHP dispersant, as shown in Fig.10, whereas, the CTAB dispersant decreased the thermal conductivity of pure water. Therefore, as expected, the CTAB dispersant led to an obvious increase in the thermal conductivity of the $\mathrm{SiO}_{2}-\mathrm{H}_{2} \mathrm{O}$ and $\mathrm{TiO}_{2}-\mathrm{H}_{2} \mathrm{O}$ nanofluids. The cause of the increase the thermal conductivity of the $\mathrm{Al}_{2} \mathrm{O}_{3}-\mathrm{H}_{2} \mathrm{O}$ nanofluid remains unclear and may be due to either the SHP dispersant or $\mathrm{Al}_{2} \mathrm{O}_{3}$ nanoparticles, or both. Further tests and analyses are still needed to better understand the underlying phenomena.
Based on the thermal conductivities of nanofluids with different types of nanoparticles, nanoparticle concentrations, and temperatures, it can be concluded that although the thermal conductivity of $\mathrm{Al}_{2} \mathrm{O}_{3}-\mathrm{H}_{2} \mathrm{O}$ was improved to some extent, it is not clear whether this was owing to the dispersants or the nanoparticles. The thermal conductivity of the $\mathrm{SiO}_{2}-\mathrm{H}_{2} \mathrm{O}$ and $\mathrm{TiO}_{2}-\mathrm{H}_{2} \mathrm{O}$ nanofluids also improved, mainly owing to the increase in the thermal and mass transfer performance due to the presence of nanoparticles in the base fluid. Therefore, the $\mathrm{TiO}_{2}-\mathrm{H}_{2} \mathrm{O}$ nanofluid was used for further analysis of the thermal conductivity in field experiments performed in an oilfield wellhead heating furnace.

\section{FIELD EXPERIMENT ON THE THERMAL PERFORMANCE OF NANOFLUIDS}

The inlet temperature, outlet temperature, temperature difference between the inlet and outlet, and water bath temperature of the TP101 heating furnace were measured on $16^{\text {th }}$ October, 2019. The results are presented in Fig.11. At 9:00, the temperature suddenly changed due to differences in the local day versus night temperatures. To ensure accurate and comparable experimental data, field data were processed, as follows.

(1) To reduce the influence of the local ambient temperature, data were collected between 0:00 and 9:00.

(2) Gas consumption of the heating furnace was taken as the average volume of accumulated gas between 23:00 and 9:00.

(3) Parameters such as liquid production and water fraction were provided by the institute of exploration and development of oil and gas in the oilfield.

(4) Natural gas caloricity was taken as the low heating value (LHV), which was $36960 \mathrm{~kJ} / \mathrm{m}^{3}$, based on the experimental report from the oilfield.

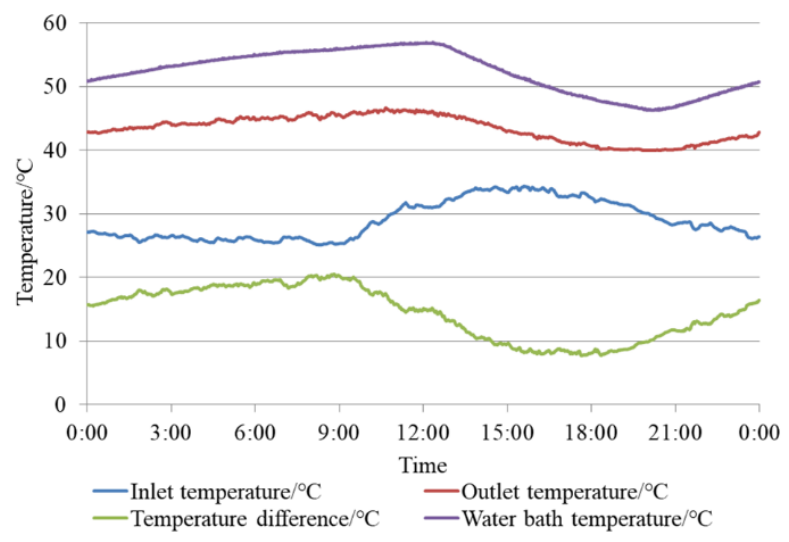

Fig. 11 Actual temperature variation of TP101 heating furnace on $16^{\text {th }}$ October, 2019

\subsection{Variation of parameters}

Variation of the heating furnace parameters, including liquid production, water content, inlet and outlet temperatures $t_{i n} / t_{\text {out }}$, and temperature difference $\Delta T$, both before and after the addition of $\mathrm{TiO}_{2}$ nanoparticles, are presented in Table 3 .

Before the nanoparticles were added, the average inlet temperature and outlet temperature on $16^{\text {th }}$ October and $17^{\text {th }}$ October were $26.08^{\circ} \mathrm{C}$ and $44.535^{\circ} \mathrm{C}$, respectively, representing a temperature difference of $18.455^{\circ} \mathrm{C}$. Following the addition of nanoparticles, the heating furnace took two days to reach the steady state. The results presented in Table 3 suggest that when nanoparticles were added, the crude oil temperature at the outlet was higher after $20^{\text {th }}$ October and the mean difference between the inlet and outlet temperature $\Delta T$ increased from $18.46^{\circ} \mathrm{C}$ to $24.18^{\circ} \mathrm{C}$, before and after, indicating that the crude oil temperature at the outlet 
greatly increased with the addition of the $\mathrm{TiO}_{2}$ nanoparticles; therefore, the heat absorption capacity of the crude oil increased.

Table 3 Parameter values adding $\mathrm{TiO}_{2}$ nanoparticles

\begin{tabular}{|c|c|c|c|c|c|}
\hline No. & Mass $(t / d)$ & $\begin{array}{c}\text { Water concent } \\
(\%)\end{array}$ & $t_{\text {in }}\left({ }^{\circ} \mathrm{C}\right)$ & $t_{\text {out }}\left({ }^{\circ} \mathrm{C}\right)$ & $\Delta T\left({ }^{\circ} \mathrm{C}\right)$ \\
\hline 1 & 46.8 & 72.63 & 24.77 & 48.85 & 24.08 \\
\hline 2 & 45.1 & 71.08 & 25.15 & 48.74 & 23.59 \\
\hline 3 & 44.9 & 72.86 & 25.28 & 48.56 & 23.28 \\
\hline 4 & 44.5 & 70.91 & 23.36 & 47.45 & 24.09 \\
\hline 5 & 44.1 & 75.56 & 23.85 & 48.92 & 25.07 \\
\hline 6 & 46.5 & 70.13 & 24.46 & 49.48 & 25.02 \\
\hline 7 & 46.5 & 70.30 & 24.00 & 48.77 & 24.77 \\
\hline 8 & 46.5 & 71.00 & 24.72 & 48.42 & 23.70 \\
\hline 9 & 46.5 & 75.27 & 24.49 & 48.26 & 23.77 \\
\hline 10 & 51.3 & 70.34 & 24.72 & 48.50 & 23.78 \\
\hline 11 & 51.3 & 70.49 & 24.17 & 49.88 & 25.71 \\
\hline 12 & 51.3 & 70.31 & 25.07 & 48.39 & 23.32 \\
\hline
\end{tabular}

\subsection{Variation of effective thermal efficiency}

The effective thermal efficiency of the heating furnace can be calculated as the ratio between the effective heat absorption of crude oil and the caloricity of the natural gas:

$$
\eta=\frac{C_{p} M\left(t_{\text {out }}-t_{\text {in }}\right)}{V_{g} Q_{g}} \times 100 \%
$$

Fig.12 shows the variation in effective thermal efficiency of the TP101 boiler furnace before and after the addition of nanoparticles. The average effective thermal efficiency without nanoparticles was $63.46 \%$. After the addition of nanoparticles, the heating furnace system gradually stabilized, and the average effective thermal efficiency increased to $74.03 \%$, an increase of $10.57 \%$. The results suggest that the effective heat absorption capacity of crude oil can be greatly improved with the addition of nanoparticles.

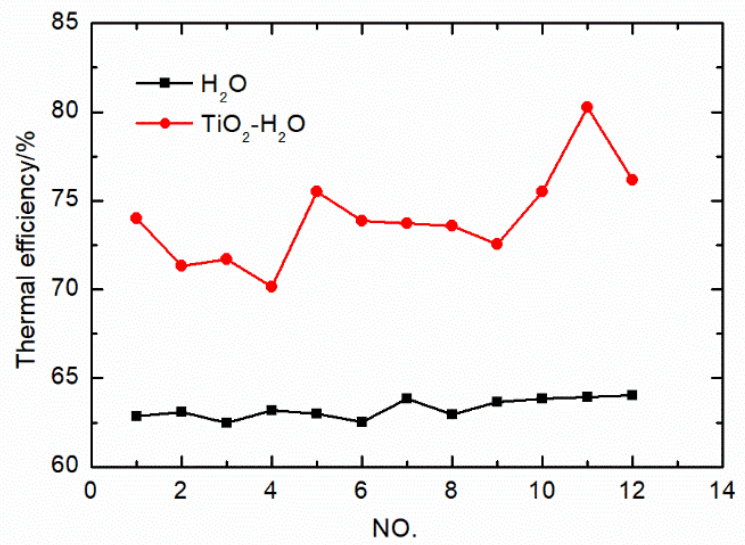

Fig. 12 Effective thermal efficiency of the TP-101 boiler furnace

\subsection{Variation of water bath temperature}

Fig.13 shows an increase in thermal conductivity of pure water when of $\mathrm{TiO}_{2}$ nanoparticles were added, and thermal conductivity also varied with nanoparticle concentration. In the field experiment, the mass concentration of nanoparticles was about $0.3 \%$. From Fig. 11, it can be observed that the average water bath temperature of the TP-101 boiler furnace rose from $52.43^{\circ} \mathrm{C}$ to $62.47^{\circ} \mathrm{C}$ during two while the nanofluid stabilized.

\subsection{Analysis of effective thermal efficiency}

Analyzing the temperature difference between inlet and outlet of crude oil and water bath temperature in the heating furnace, the effective heat absorption efficiency of crude oil was found to increase with the addition of nanoparticles. To determine the main factors affecting the increase in the amount of heat absorbed by the crude oil, the logarithmic average temperature difference for heat transfer was proposed. The logarithmic mean temperature difference increased from $15.29^{\circ} \mathrm{C}$ to $23.87^{\circ} \mathrm{C}$, as shown in Fig.14, indicating that heat transfer between the smoke and water of the heating furnace was strengthened, thereby increasing the water bath temperature, and ultimately, increasing the effective heat absorption by the crude oil.

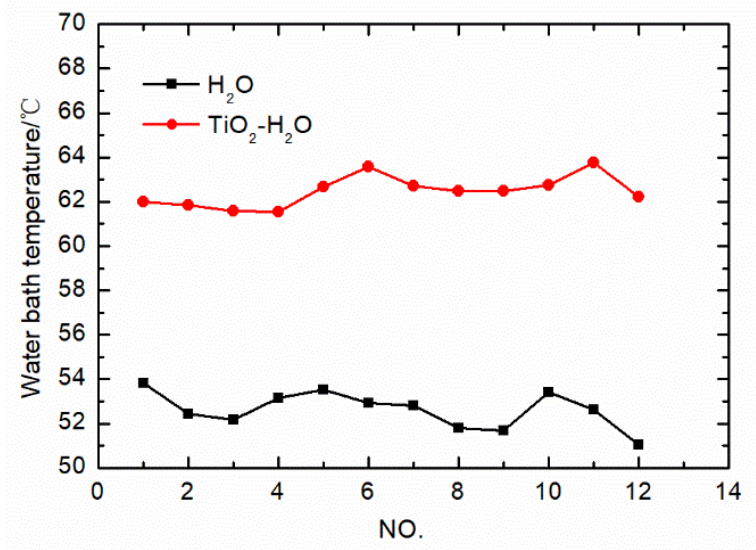

Fig. 13 Variation of water bath temperature of the TP-101 boiler furnace

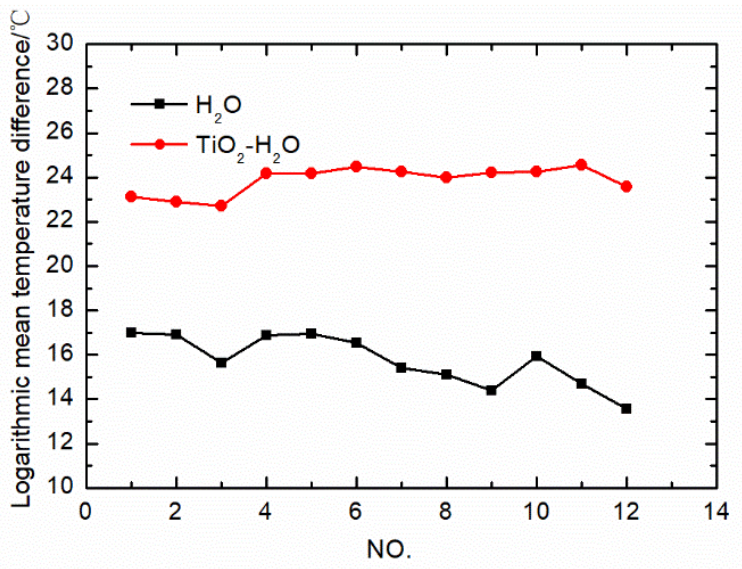

Fig. 14 Logarithmic mean heat transfer temperature of the TP-101 boiler furnace

\section{CONCLUSIONS}

In this study, three stable nanofluids were prepared using a two-step method. Different dispersants and nanoparticles were investigated, and the variation of thermal conductivity with nanoparticle concentration, dispersant concentration, and temperature, were analyzed in order to assess the overall thermal performance of the nanofluids. A suitable nanofluid was selected for the field experiment in a real oilfield in Xinjiang, China. The main conclusions can be summarized as follows:

(1) To assess the heat transfer mechanism and stability of nanofluids with different nanoparticle and dispersant concentrations, thermal conductivity was measured at different temperatures. Compared with pure water, the $\mathrm{TiO}_{2}$ nanoparticles and CTAB dispersant increased the thermal conductivity by $5.38 \%$ at concentrations of $0.75 \%$ and $0.375 \%$, respectively.

(2) For the first time, a field experiment was performed with nanofluids and the results were used to evaluate the heat transfer performance of the nanofluid. Following the addition of nanoparticles, the effective heat absorption efficiency of the TP-101 boiler furnace increased from $63.46 \%$ to $74.03 \%$ and the temperature in the water bath 
increased by $10.57 \%$. The results suggest that heat exchange between the smoke and water of the heating furnace can be strengthened, which can increase water bath temperature, and ultimately, increase the effective heat absorption of crude oil. Based on the results of the field experiment, $14.8 \mathrm{~m}^{3} /$ day or $5400 \mathrm{~m}^{3} /$ year of natural gas can be saved.

(3) It is not known how long nanofluids remain stable and maintain their initial heat transfer performance during operation. Nanoparticles may accumulate on the wall of the fire tube or smoke tube, forming a layer of nanoparticles, which could enhance or inhibit heat transfer. The influence of nanofluid stability under long-term operating conditions on thermal performance, as well as the effects of nanoparticle deposition on the fire tube and smoke tube walls, should be considered in future work.

\section{ACKNOWLEDGEMENTS}

The authors wish to express their sincere gratitude to the peer reviewers, for their helpful suggestions and valuable comments, which have improved the paper appreciably. And this work was supported by National Natural Science Foundation of China (Grant no. 51961135102) and Shaanxi Science and Technology Foundation (Grant no. 2020JQ774).

\section{NOMENCLATURE}

$C_{\mathrm{p}} \quad$ Specific thermal capacity of liquid production, $\mathrm{kJ} /\left(\mathrm{kg} \cdot{ }^{\circ} \mathrm{C}\right)$;

$Q \quad$ Natural gas caloricity, $\mathrm{kJ} / \mathrm{m}^{3}$;

$V \quad$ Natural gas consumption, $\mathrm{m}^{3}$;

$M \quad$ Liquid production, $\mathrm{kg} / \mathrm{s}$;

$\Delta T \quad$ Temperature difference, ${ }^{\circ} \mathrm{C}$;

$t \quad$ Temperature, ${ }^{\circ} \mathrm{C}$.

Greek Symbols

$\eta \quad$ Effective thermal efficiency;

$\lambda \quad$ Thermal conductivity, $\mathrm{W} /(\mathrm{m} \cdot \mathrm{K})$.

Subscripts

g Gas

out Outlet

in Inlet

\section{REFERENCES}

Abbud, L. H., Balla, H. H., Abdulwahid, A. F., and Karim, Z. S., 2019, Study of thermal and mechanical properties of fiber-glass multi-wall carbon nanotube/EPOXY, Frontiers in Heat and Mass Transfer, 13, 1-8. https://doi.org/10.5098/hmt.13.30

Amiri, A., Shanbedi, M., Amiri, H., Heris, S. Z., Kazi, S.N., Chew, B.T., and Eshghi, H., 2014, Pool boiling heat transfer of CNT/water nanofluids, Applied Thermal Engineering, 71(1): 450-459.

https://doi.org/10.1016/j.applthermaleng.2014.06.064

Bierman, B., Treynor, C., O’Donnell, J., Lawrence, M., Chandra, M., Farver, A., Behrens, P.von, and Lindsay, W., 2014. Performance of an enclosed trough EOR system in south oman. Energy Procedia, 49, 12691278.

https://doi.org/10.1016/j.egypro.2014.03.136

Chang, X.H., Zhao, Y., Hao, Y., Xu, M. Y., and Yao, L.R., 2020, Quantitative experimental research on nanofluid in heating system of crude oil, Modern Chemical Industry, 2020, 40(6):160-164.

https://doi.org/10.16606/j.cnki.issn0253-4320.2020.06.033

Dolatiasl, K., Bakhshan, Y., Abedini, E., and Niazi, S., 2020, Numerical investigation of critical heat flux in subcooled flow boiling of nanofluids, Journal of Thermal Analysis and Calorimetry, 139(3):2295-2308. https://doi.org/10.1007/s10973-019-08616-8
Jung, J.Y., Kim, E.S., and Kang, Y.T., 2012, Stabilizer effect on CHF and boiling heat transfer coefficient of alumina/water nanofluids. International Journal of Heat and Mass Transfer, 55(7-8): 1941-1946. https://doi.org/10.1016/j.ijheatmasstransfer.2011.11.049

Kamatchi, R., Venkatachalapathy, S., and Nithya, C., 2016, Experimental investigation and mechanism of critical heat flux enhancement in pool boiling heat transfer with nanofluids. Heat and Mass Transfer, 52: 2357-2366.

https://doi.org/10.1007/s00231-015-1749-2

Kangude, P., Bhatt, D., and Srivastava, A., 2018, Experiments on the effects of nanoparticles on subcooled nucleate pool boiling, Physics of Fluids, 30(5):057105. https://doi.org/10.1063/1.5027295

Kathiravan, R., Kumar, R., Gupta, A., and Chandra, R., 2010, Preparation and pool boiling characteristics of copper nanofluids over a flat plate heater. International Journal of Heat and Mass Transfer, 53(910):1673-1681.

https://doi.org/10.1016/j.ijheatmasstransfer.2010.01.022

Mao, N., Hao, J. Y., He, T. B., Xu, Y. J., Song, M. J., and Tang, J. F., 2020, Unsteady heat transfer properties of spray falling over a horizontal tube in an oily sewage source heat pump[J]. Applied Thermal Engineering, 179, 115675:1-11.

https://doi.org/10.1016/j.applthermaleng.2020.115675

Nazari, M.A., Ghasempour, R., Ahmadi, M.H., Heydarian, G., and Shafii, M. B., 2018, Experimental investigation of graphene oxide nanofluid on heat transfer enhancement of pulsating heat pipe. International Communications in Heat and Mass Transfer, 91:90-94. https://doi.org/10.1016/j.icheatmasstransfer.2017.12.006

Niu, G. W., and Li, J., 2015, Comparative studies of pool boiling heat transfer with nano-fluids on porous surface. Heat and Mass Transfer, 51(12):1769-1777.

https://doi.org/10.1007/s00231-015-1542-2

Sarafraz, M.M., and Hormozi, F., 2014, Scale Formation and SubcooledFlow Boiling Heat Transfer of CuO-Water Nanofluid Inside the Vertical Annulus, Experimental Thermal and Fluid Science, 52: 205-214. https://doi.org/10.1016/j.expthermflusci.2013.09.012

Setoodeh, H., Keshavarz, A., Ghasemian, A., and Nasouhi, A., 2015, Subcooled-Flow Boiling of Alumina/water Nanofluid in a Channel with a Hot Spot: An Experimental Study, Applied Thermal Engineering, 90: 384-394.

https://doi.org/10.1016/j.applthermaleng.2015.07.016

Shahmoradi, Z., Etesami, N., and Esfahany, M.N., 2013, Pool boiling characteristics of nanofluid on flat plate based on heater surface analysis. International Communications in Heat and Mass Transfer, 47(10):113120. https://doi.org/10.1016/j.icheatmasstransfer.2013.06.006

Sheikholeslami, M., Darzi, M., and Sadoughi, M.K., 2018, Heat transfer improvement and pressure drop during condensation of refrigerant-based nanofluid; an experimental procedure. International Journal of Heat and Mass Transfer, 122:643-650.

https://doi.org/10.1016/j.ijheatmasstransfer.2018.02.015

Teja, S.R., Moorthy, C. V. K. N. S. N., Jayakumar, S., Kumar, A. K., and Srinivas, V., 2020, Ethylene glycol-based nanofluids-estimation of stability and thermophysical properties. Frontiers in Heat and Mass Transfer, 15, 1-9.

http://www.thermalfluidscentral.org/journals/index.php/Heat_Mass_Tra nsfer/article/view/1120 
Wang, D.M., Quan, X.J., and Li, J.J., 2018, Progress in the researches on enhancement effects of nanofluids on boiling heat transfer, Material China, 37(12):1033-1038.

https://doi.org/10.7502/j.issn.1674-3962.2018.12.11

Wen, D. S., Michael, C., Hu, X., and Lin, G. P., 2011, Boiling heat transfer of nanofluids: The effect of heating surface modification. International Journal of Thermal Science, 50(4):480-485. https://doi.org/10.1016/j.ijthermalsci.2010.10.017

Wu, Z., Feng, Z.Z., Bengt, S., and Lars, W., 2014, A comparative study on thermal conductivity and rheology property of alumina and multiwalled carbon nanotube nanofluids, Frontiers in Heat and Mass Transfer, 5,18, 1-10.

http://dx.doi.org/10.5098/hmt.5.18 